\title{
New Convenient Synthesis of 8-C-Methylated Homoisoflavones and Analysis of Their Structure by NMR and Tandem Mass Spectrometry
}

\author{
Santosh Kumar Yadav1,2 \\ ${ }^{1}$ Department of Organic Chemistry \& FDW, Andhra University, Visakhapatnam, India \\ ${ }^{2}$ DMPK, Sai Life Sciences Ltd., Pune, Maharashtra, India \\ Email: skgoityadav@gmail.com
}

How to cite this paper: Yadav, S.K. (2021) New Convenient Synthesis of 8-C-Methylated Homoisoflavones and Analysis of Their Structure by NMR and Tandem Mass Spectrometry. International Journal of Organic Chemistry, 11, 46-54.

https://doi.org/10.4236/ijoc.2021.111005

Received: January 27, 2021

Accepted: March 26, 2021

Published: March 29, 2021

\section{Copyright $\odot 2021$ by author(s) and} Scientific Research Publishing Inc. This work is licensed under the Creative Commons Attribution International License (CC BY 4.0).

http://creativecommons.org/licenses/by/4.0/

\begin{abstract}
Homoisoflavonoids are in the subclass of the larger family of flavonoids having one more alkyl carbon than flavonoids. Among them, 8-C-Methylated homoisoflavones have not been extensively studied for synthesis and biological evaluation. Author's current objective is to synthesize 8-C-Methylated homoisoflavones by the reaction of 3-C-methylated dihydrochalcones with $\mathrm{N}, \mathrm{N}^{\prime}$-dimethyl (chloromethylene) ammonium chloride generated in situ from DMF and $\mathrm{PCl}_{5}$ for one carbon extension at about room temperature. The 3-C-methylated dihydrochalcones were synthesized by the reduction of 3-Cmethylated chalcones, which were prepared from 3-C-methylated acetophenones and aromatic aldehydes in the presence of base. All the synthesized novel homoisoflavones's structures were characterized by NMR and Tandem Mass Spectrometry.
\end{abstract}

\section{Keywords}

8-C-Methylated Homoisoflavones, 3-C-Methylated Dihydrochalcones,

3-C-Methylated Chalcones, 3-C-Methylated Acetophenones,

Dimethylformamide, $\mathrm{BF}_{3} \cdot \mathrm{Et}_{2} \mathrm{O}, \mathrm{PCl}_{5}$

\section{Introduction}

The homoisoflavonoids were classified into five groups based on their structures: sappanin-type (I), scillascillin-type (II), brazilin-type (III), caesalpin-type (IV), and protosappanin-type (V) [1], Figure 1 shows the structure of all the five types of homoisoflavonoids. 3-Benzylchromones, the sub-group of sappanin-type ho- 
moisoflavonoids, mainly found in the plants of Fabaceae (genus Cassia) and Asparagaceae families (genus Ophiopogon) [1] [2]. Almost all are hydroxy-substituted at $\mathrm{C}-5$ in ring $\mathrm{A}$, and usually hydroxyl-, methoxy-, and/or methylenedioxy-substituted at C-7 in ring A, as well as at C-2', C-3', and C-4' in ring B [3] [4] [5]. Additionally, methyl and/or formyl substituted can be found at C-6 and C-8 in ring $\mathrm{A}$ in compounds isolated from the genus Ophiopogon [5] [6] [7]. The methyl substituent at C-7 was reported from the genus Cassia [8]. Some naturally occurring 3-benzylchromene-4-ones are shown in Figure 2.
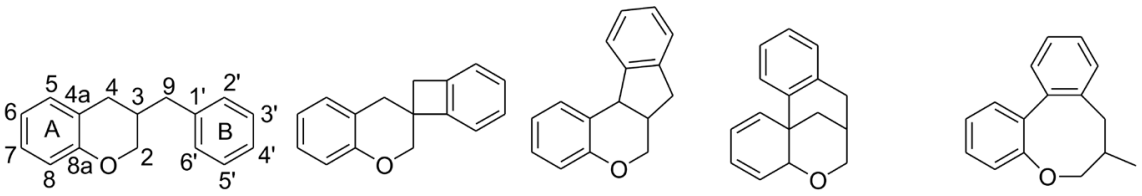

(a) Sappanin-type

(b) Scillascillin type (c) Brazilin type (d) Caesalpin-type (e) Protosappanin-

Figure 1. Different types of Homoisoflavonoids<smiles>Cc1c(O)c(C)c2occ(Cc3ccc4c(c3)OCO4)c(=O)c2c1O</smiles>

Methylophiopogonone A<smiles>Cc1c(O)cc(O)c2c(=O)c(Cc3ccc4c(c3)OCO4)coc12</smiles>

lsoophiopogonone A<smiles>COc1cc2occ(Cc3ccc(O)c(O)c3)c(=O)c2c(O)c1C</smiles><smiles>COc1ccc(Cc2coc3c(C)c(O)c(C)c(O)c3c2=O)cc1</smiles>

Methylophiopogonone B<smiles>Cc1c(O)cc2occ(Cc3ccc4c(c3)OCO4)c(=O)c2c1O</smiles>

Ophiopogonone A<smiles>COc1ccc(Cc2coc3cc(O)c(C)c(O)c3c2=O)cc1</smiles>

Ophiopogonone B<smiles>Cc1c(O)cc(O)c2c(=O)c(Cc3ccc(O)cc3)coc12</smiles>

Desmethylisoophiopogonone B

5-Hydroxy-7-methoxy-6-methyl-3-<smiles>Cc1c(O)cc2occ(Cc3ccc(O)cc3)c(=O)c2c1O</smiles>

$\mathrm{HO}$<smiles>Cc1cc(O)c2c(=O)c(Cc3ccc(O)cc3)coc2c1</smiles>

5, 7-Dihydroxy-3-(4'hydroxybenzyl)chromene-4-one<smiles>Cc1c(O)c(COc2ccccc2)c2occ(Cc3ccc4c(c3)OCO4)c(=O)c2c1O</smiles>

Ophiopogonone $\mathrm{C}$<smiles>Cc1c(O)c(C=O)c(O)c2c(=O)c(Cc3ccc4c(c3)OCO4)coc12</smiles>

6-formyl-isoophiopogonone $A$<smiles>COc1ccc(Cc2coc3c(C)c(O)c(C=O)c(O)c3c2=O)cc1</smiles>

6-formyl-isoophiopogonone B<smiles>Cc1c(O)cc2occ(Cc3ccc4c(c3O)OCO4)c(=O)c2c1O</smiles>

5, 7,2'-Trihydroxy-6-methyl-3-(3', 4'methylenedioxybenzyl)-chromene-4-one

2'-Hydroxy-6-methylophiopogonone A<smiles>Cc1c(O)cc2occ(Cc3ccc(O)cc3O)c(=O)c2c1O</smiles>

5, 7-Dihydroxy-6-methyl-3-(2', 4'dihydroxybenzyl)-chromene-4-one<smiles>Cc1c(O)cc(O)c2c(=O)c(Cc3ccc4c(c3)OCO4)coc12</smiles>

5, 7,2'-Trihydroxy-8-methyl-3-(3', 4'methylenedioxybenzyl)-chromene-4-one

Figure 2. Some examples of naturally occurring 3-benzylchromene-4-ones substituted in various positions. 
Various 3-benzylchromene-4-ones have been reported with a broad range of bioactivities, including angioprotective, antiallergic and antihistaminic properties [9]. In view of the increasing interest on homoisoflavanoids, several organic chemists do the research on isolation, synthesis and applications of homoisoflavanoids and their derivatives since last two decades. In this context the author has synthesized several 8-C-methylated homoisoflavones which are not studied very well in the literature.

\section{Present Work}

8-C-Methylated homoisoflavones $(9 \mathbf{a}-\mathbf{i})$ were synthesized by the reaction of 3-C-methylated dihydrochalcones (8a-i) with N,N'-dimethyl(chloromethylene)ammonium chloride generated in situ from $\mathrm{BF}_{3} \cdot \mathrm{Et}_{2} \mathrm{O}, \mathrm{DMF}$ and $\mathrm{PCl}_{5} / \mathrm{DMF}$ complex [10] for one carbon extension at about room temperature. 3-C-methylated dihydrochalcones $(\mathbf{8} \mathbf{a}-\mathbf{i})$ were prepared from 3-C-methylated chalcones $(7 \mathbf{a}-\mathbf{i})$ in methanol by passing hydrogen gas in presence of $10 \% \mathrm{Pd}-\mathrm{C}$ at room temperature where as $3-\mathrm{C}$-methylated chalcones $(7 \mathbf{a}-\mathbf{i})$ were prepared by the condensation of 2-hydroxy-3-methyl-4, 6-dimethoxy acetophenone (5) with substituted benzaldehydes in the presence of strong base $(\mathrm{KOH})$ in ethanol at room temperature as shown in Scheme 1.

2-hydroxy-3-methyl-4, 6-dimethoxy acetophenone (5) has been prepared from<smiles>COc1cc(OC)c(C(C)=O)c(O)c1C</smiles>

5<smiles>[R]c1c([R])c([R])c(CO)c([R])c1[R]</smiles>

6 (i)<smiles>[R]c1c([R])c([R])c(/C=C/C(=O)c2c(OC)cc(OC)c(C)c2O)c([R])c1[R]</smiles>

$7 \mathbf{a}-\mathbf{i}$ (ii)

\begin{tabular}{l|lllll} 
& $\mathrm{R}_{1}$ & $\mathrm{R}_{2}$ & $\mathrm{R}_{3}$ & $\mathrm{R}_{4}$ & $\mathrm{R}_{5}$ \\
\hline $\mathrm{A}$ & $\mathrm{H}$ & $\mathrm{OCH}_{3}$ & $\mathrm{H}$ & $\mathrm{H}$ & $\mathrm{H}$ \\
$\mathrm{B}$ & $\mathrm{H}$ & $\mathrm{OCH}_{3}$ & $\mathrm{OCH}_{3}$ & $\mathrm{H}$ & $\mathrm{H}$ \\
$\mathrm{C}$ & $\mathrm{H}$ & $\mathrm{H}$ & $\mathrm{Cl}$ & $\mathrm{H}$ & $\mathrm{H}$ \\
$\mathrm{D}$ & $\mathrm{H}$ & $\mathrm{OCH}_{3}$ & $\mathrm{OCH}_{3}$ & $\mathrm{OCH}_{3}$ & $\mathrm{H}$ \\
$\mathrm{E}$ & $\mathrm{H}$ & $\mathrm{H}$ & $\mathrm{Br}$ & $\mathrm{H}$ & $\mathrm{H}$ \\
$\mathrm{F}$ & $\mathrm{OCH}$ & $\mathrm{H}$ & $\mathrm{OCH}$ & $\mathrm{H}$ & $\mathrm{H}$ \\
$\mathrm{G}$ & $\mathrm{OCH}$ & $\mathrm{H}$ & $\mathrm{OCH}_{3}$ & $\mathrm{H}$ & $\mathrm{OCH}$ \\
$\mathrm{H}$ & $\mathrm{H}$ & $\mathrm{O}-\mathrm{CH}_{2}-\mathrm{O}_{3}$ & $\mathrm{H}$ & $\mathrm{H}$ \\
$\mathrm{I}$ & $\mathrm{H}$ & $\mathrm{H}$ & $\mathrm{OC}_{2} \mathrm{H}_{5}$ & $\mathrm{H}$ & $\mathrm{H}$
\end{tabular}<smiles>[R]c1c([R])c([R])c(CCC(=O)c2c(OC)cc(OC)c(C)c2O)c([R])c1[R]</smiles><smiles>[R]c1c([R])c([R])c(Cc2coc3c(C)c(OC)cc(OC)c3c2=O)c([R5])c1[R]</smiles>

9a-i

Scheme 1. Reagents \& Conditions: (i) $\mathrm{KOH}, \mathrm{EtOH}$, (ii) $\mathrm{H}_{2}$-gas, $10 \% \mathrm{Pd}-\mathrm{C}, \mathrm{MeOH}$, (iii) $\mathrm{BF}_{3} \cdot \mathrm{Et}_{2} \mathrm{O}, \mathrm{DMF}, 10^{\circ} \mathrm{C}$; (iv) $\mathrm{PCl}_{5} / \mathrm{DMF}, 60^{\circ} \mathrm{C}, 30-40 \mathrm{~min}$. 


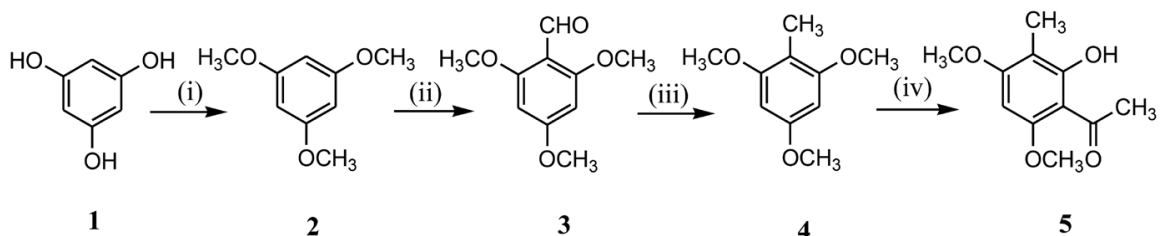

Scheme 2. Reagents \& Conditions: (i) DMS, dry acetone, $\mathrm{K}_{2} \mathrm{CO}_{3}$; (ii) $\mathrm{DMF}, \mathrm{POCl}_{3}$; (iii) Ethylene glycol, hydrazine hydrate, $\mathrm{KOH}, 135^{\circ} \mathrm{C}-145^{\circ} \mathrm{C}$; (iv) $\mathrm{CH}_{3} \mathrm{COCl}, \mathrm{AlCl}_{3}, \mathrm{MDC}$, $0^{\circ} \mathrm{C}$.

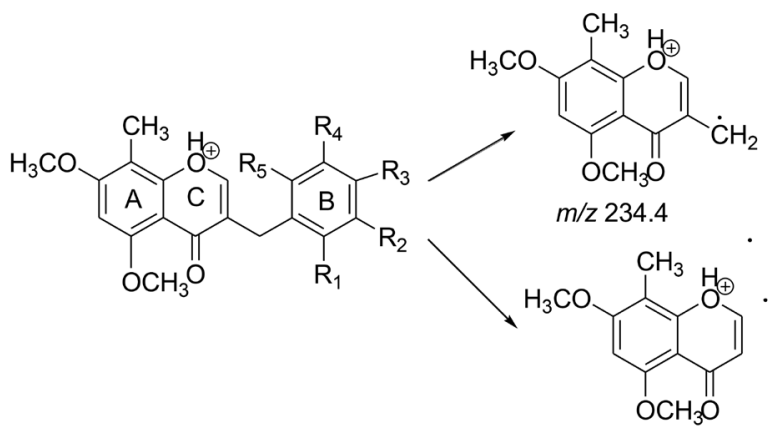

$\mathrm{m} / \mathrm{z} 221.3$

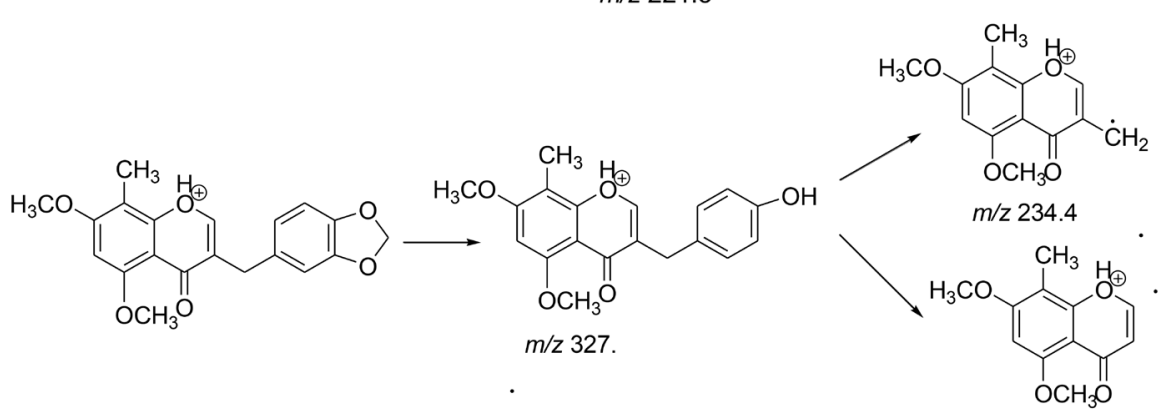

$\mathrm{m} / \mathrm{z} 221.3$

Scheme 3. Proposed MS fragmentation pathway for the $[\mathrm{M}+\mathrm{H}]^{+}$ions of Compounds $9 \mathrm{a}$ to $9 \mathrm{i}$.

commercially available phloroglucinol using regular conventional methods like methylation (2) [11], formylation (3) [12], Wolf-Kishner reduction(4) [13] and acetylation (5) [12] in good yields as shown in Scheme 2.

All the intermediates were confirmed by comparing the spectral data and melting points with the literature (Scheme 3 ).

\section{Results and Discussion}

${ }^{1} \mathrm{H}$ NMR and ${ }^{13} \mathrm{C}$ NMR of chalcones, dihydrochalcones and homoisoflavones

In the ${ }^{1} \mathrm{H}$ NMR spectra of the chalcones, the characteristic resonance signals for $\alpha$ and $\beta$ protons appeared in the region $\delta 7.60-7.90$ and $\delta 7.70-8.12$ as doublets respectively. The H-5 aromatic protons were observed in the region $\delta 6.27$ 6.29. The methoxyl and methyl groups on the aromatic rings displayed signals as singlets in the region $\delta 3.84-3.98$ and $\delta 1.93$ to 2.04 respectively. The hydroxyl protons $(\mathrm{OH}$ at $\mathrm{C}-2)$ displayed signals in the region $\delta 13.89-14.29$. In the ${ }^{13} \mathrm{C}$ NMR Spectra of the chalcones, the resonance signals for the carbonyl carbons 
$(\mathrm{C}=\mathrm{O})$ were located in the region $\delta 192.3$ - 194.5. The chemical shifts for $\alpha, \beta$ methylene carbons were observed in the region $\delta 126.1-129.2$ and $\delta 139.4$ 142.1 respectively. The phenolic carbons signals were found in the range $\delta 163.5$ - 164.2 whereas the aromatic methoxyl carbons $\left(\mathrm{Ar}-\mathrm{OCH}_{3}\right)$ were observed in the region $\delta 55.2$ - 55.9. The methyl group carbons $\left(\mathrm{Ar}-\mathrm{CH}_{3}\right)$ signal were found in the region $\delta 7.1-7.8$ [14].

In the ${ }^{1} \mathrm{H}$ NMR Spectra of the dihydrochalcones, the characteristic resonance signals for $\alpha$ and $\beta$ protons appeared in the region $\delta 3.10-3.36$ and $\delta 2.74-2.90$ as triplets respectively. The H-5 aromatic protons appeared in the region $\delta 6.27$ 6.29. The methoxyl and methyl groups attached to the aromatic rings displayed proton signals as singlets in the region $\delta 3.84-3.95$ and $\delta 1.93$ to 2.04 respectively. The hydroxyl protons $(\mathrm{OH}$ at $\mathrm{C}-2)$ displayed signals in the region $\delta 13.90$ - 14.42. In the ${ }^{13} \mathrm{C}$ NMR Spectra of the dihydrochalcones, the resonance signals for the carbonyl carbons $(\mathrm{C}=\mathrm{O})$ were located in the region $\delta 201.6-204.8$. The chemical shifts for $\alpha, \beta$ methylene carbons were observed in the region $\delta 39.0$ 40.9 and $\delta 26.4-30.4$ respectively. The phenolic carbons signals were found in the range $\delta 162.8-164.4$ whereas the aromatic methoxyl carbons $\left(\mathrm{Ar}-\mathrm{OCH}_{3}\right)$ were observed in the region $\delta 55.2$ - 55.9. The methyl group carbon $\left(\mathrm{Ar}-\mathrm{CH}_{3}\right)$ signal was found in the region $\delta 7.1-7.9$.

In the $1 \mathrm{H}$ NMR Spectra of the 8 -C-methylated homoisoflavones, the characteristic resonance signals for the $\mathrm{H}-2$ and $\mathrm{H}-9$ were observed as singlets in the region $\delta 7.95-8.14$ and $\delta 3.45-3.61$ respectively. The aromatic protons of homoisoflavones were observed between $\delta 6.13$ and $\delta 7.69$ depending on the nature of the substituents on the aromatic rings. The methoxyl groups and methyl group on the aromatic rings displayed their proton signals in the region $\delta 3.84$ 3.98 and $\delta 1.93-2.04$ as singlets respectively. In the ${ }^{13} \mathrm{C}$ NMR spectra of the homoisoflavones, the resonance signals for the carbonyl carbons $(\mathrm{C}=\mathrm{O})$ were located in the region $\delta 176.4-180.8$. The chemical shifts for the olefinic carbons, $\mathrm{C}-2$ and C-3 were observed in the region $\delta 153.2-154.8$ and $\delta 120.8-121.5$ respectively. The carbon signal for C-9 was observed near $\delta 29.3-30.4$. The methoxyl and methyl group carbons attached to aromatic rings showed signals in the region $\delta 55.2-55.9$ and $\delta 7.2-7.7$ respectively.

Figure 3 is the ${ }^{1} \mathrm{H}$ NMR Spectrum of 3-(3', 4', 5'-trimethoxybenzyl)-5, 7-dimethoxy-8-methyl-4H-chromen-4-one (9d), which is a typical spectrum of this group of compounds.

Figure 4 is the ${ }^{13} \mathrm{C}$ NMR Spectrum of 3-(3', 4', 5'-trimethoxybenzyl)-5, 7-dimethoxy-8-methyl-4H-chromen-4-one (9d), which is a typical spectrum of this group of compounds.

Tandem Mass spectrometry of homoisoflavones

For MS/MS analysis, a 4000 QTRAP mass spectrometer (AB SCIEX, Toronto, Canada) was used having Analyst 1.6.3 software. To tune the mass spectrometer, a $1000 \mathrm{ng} / \mathrm{ml}$ solution of pure compounds $9 \mathrm{a}-9 \mathrm{i}$ in acetonitrile $(\mathrm{MeCN})$ were respectively injected into the source by continuous infusion. The mass spectrometer parameters were adjusted as source temperature $500{ }^{\circ} \mathrm{C}$, Heater gas 60 (nitrogen) psi, 


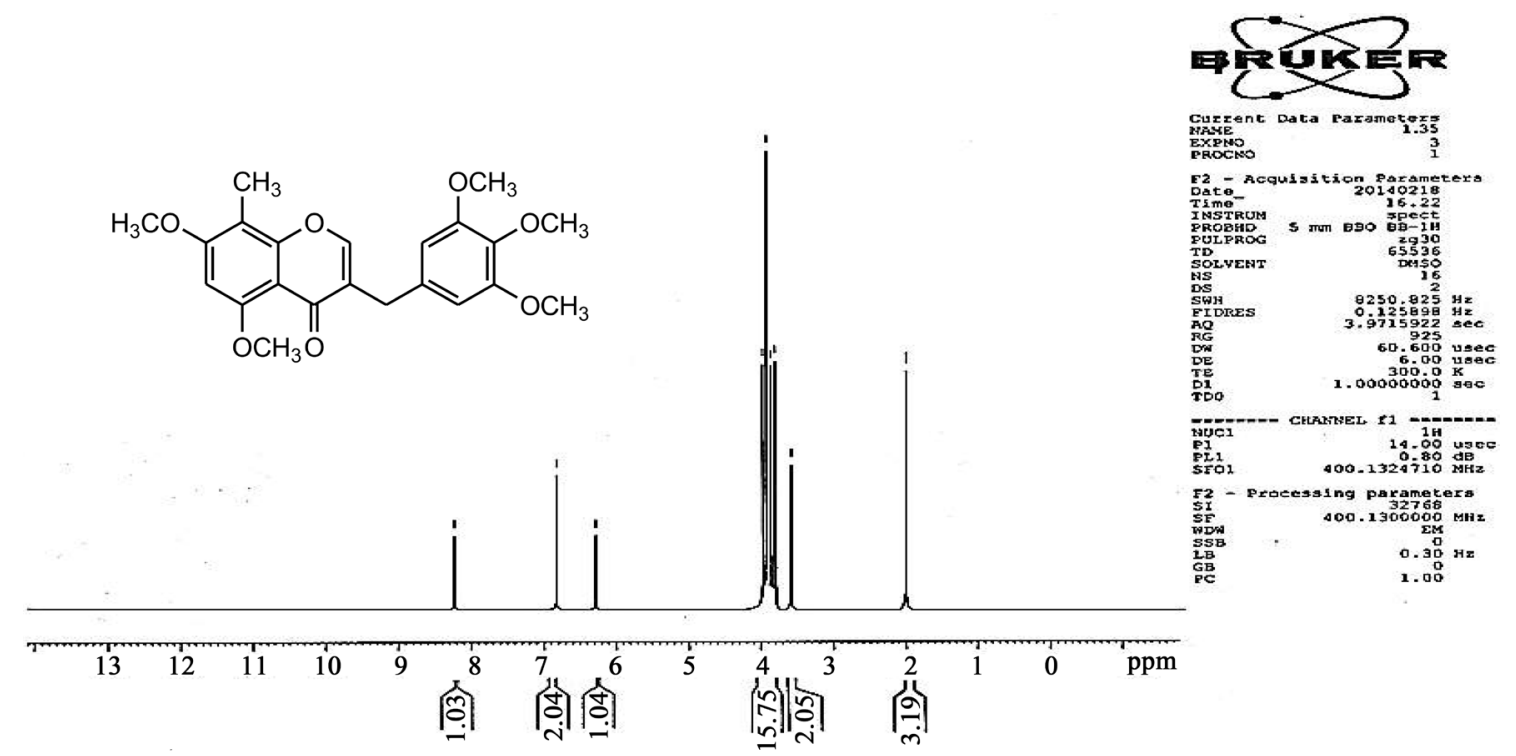

Figure 3. 'HNMR spectrum of 3-(3', 4', 5'-trimethoxybenzyl)-5, 7-dimethoxy-8-methyl-4H-chromen-4-one(9d).

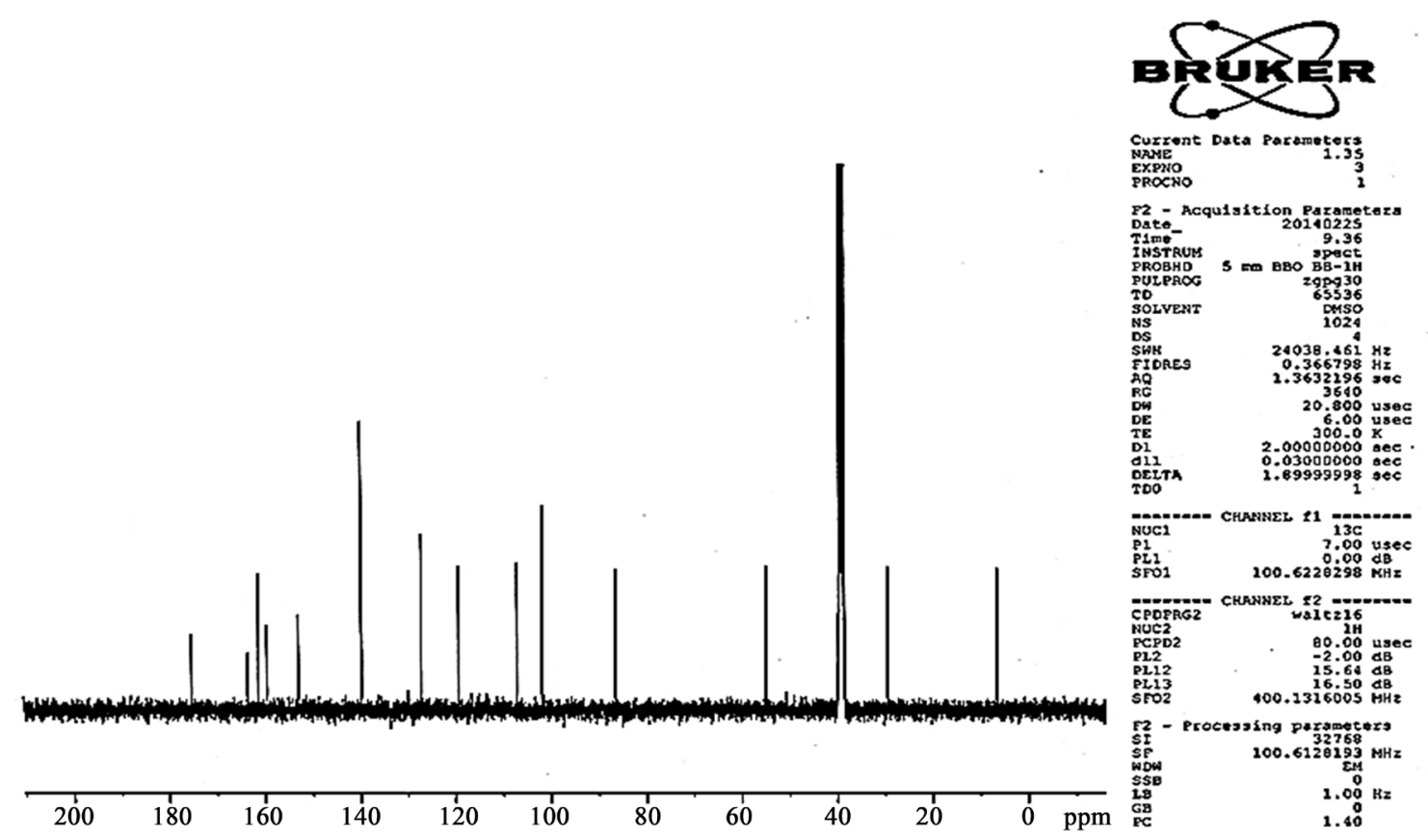

Figure 4. ${ }^{13} \mathrm{CNMR}$ spectrum of 3-(3', 4', 5'-trimethoxybenzyl)-5,7-dimethoxy-8-methyl-4H-chromen-4-one(9d).

Nebulizer gas 40 (nitrogen) psi, Curtain gas 25 (nitrogen) psi, CAD gas 5 (nitrogen) psi, Ion Spray (IS) voltage 5500 volts, Source flow rate $20 \mu \mathrm{l} / \mathrm{min}$ without split.

APCI and ESI sources were tried for the ionization of homoisoflavonoids both in positive and negative ion modes. Base peak in positive mode gave the good intensity rather than in negative mode where base peak obtained with remarkably lower intensity. APCI and ESI produced very similar ions. Therefore, ESI in the positive ion mode was selected as the ion source for follow-up analyses. For full scan MS analysis, the spectra were recorded in the range of m/z $200-500$ 
$\mathrm{Da}$, Figure 5 shows the parent ion $(\mathrm{M}+\mathrm{H})^{+}$of compound $9 \mathrm{a}$ at 341.2 . The isolation width of precursor ions was 3.0 mass units. During MS/MS product-ion analysis of compounds 9 a to $9 \mathrm{i}$, two common fragment ions at $\mathrm{m} / \mathrm{z} 234.4$ and 221.3 were observed which revealed that the major fragment ions occurred by the cleavage of C3-9 or C9-1' bonds to lose the B-ring (Scheme 3). Figure 6

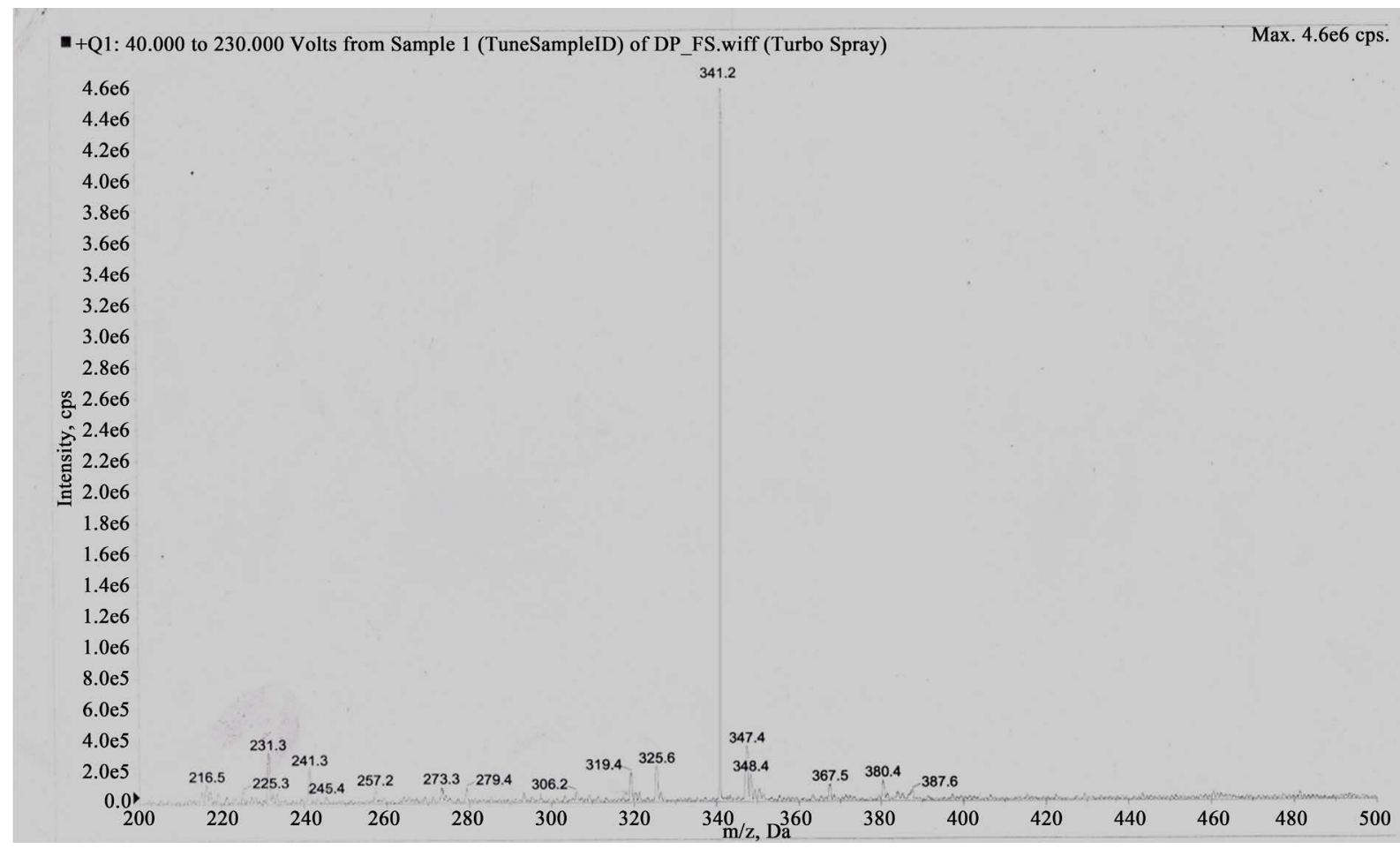

Figure 5. Full Scan MS spectrum of the Compound $(9 a),(M+H)^{+}$.

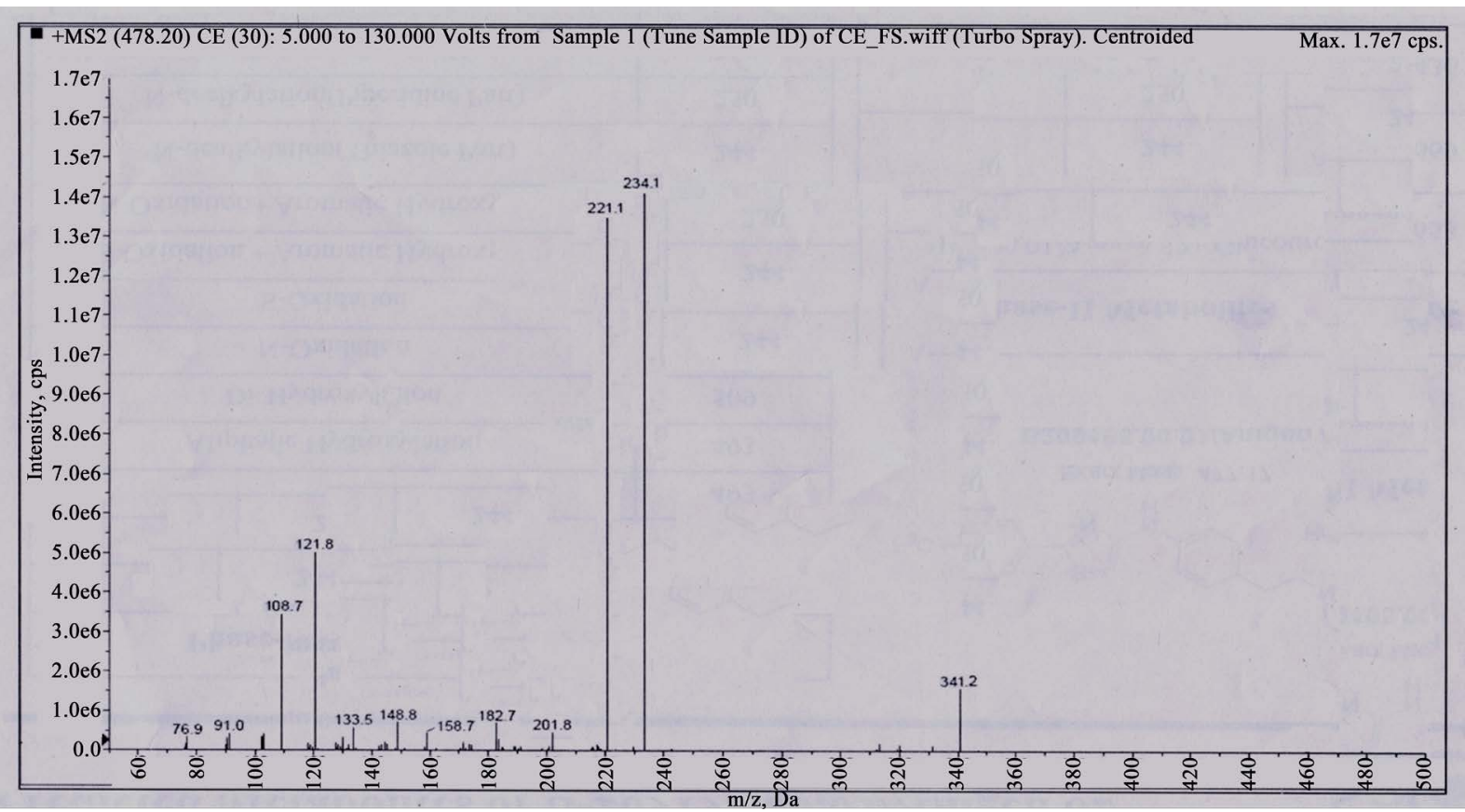

Figure 6. $\mathrm{MS}_{2}$ spectrum of the Compound (9a), $(\mathrm{M}+\mathrm{H})^{+},\left(341 \_234\right.$ \& 341_221). 
shows the daughter ions at 234.1 and 221.1 of compound 9a. Except $9 \mathrm{H}$ where first step was the conversion of methylenedioxy group at B-ring into a hydroxyl group, and then underwent the cleavage of $\mathrm{C} 3-9$ or $\mathrm{C} 9-1$ ' bonds to lose the B-ring. For compounds $9 e$, both $(\mathrm{M}+\mathrm{H})^{+}$and $(\mathrm{M}+2 \mathrm{H})^{+}$were obtained as prominent peak.

\section{Conclusion}

The author has developed a mild, efficient, and economical method for the synthesis of 8-C-methylated homoisoflavones using the $\mathrm{PCl}_{5} / \mathrm{DMF}$ complex. Operational simplicity, mild reaction conditions, short reaction times, and good yields are the notable advantages of this method. Study of biological activities and preclinical research of synthesized compounds are under progress.

\section{Conflicts of Interest}

The author declares no conflicts of interest regarding the publication of this paper.

\section{References}

[1] Lin, L.G., Liu, Q.Y. and Ye, Y. (2014) Naturally Occurring Homoisoflavonoids and Their Pharmacological Activities. Planta Med., 80, 1053-1066. https://doi.org/10.1055/s-0034-1383026

[2] Abegaz, B.M., Mutanyatta-Comar, J. and Nindi, M. (2007) Naturally Occurring Homoisoflavonoids: Phytochemistry, Biological Activities and Synthesis. Natural Product communications, 2, 475-498. https://doi.org/10.1177/1934578X0700200418

[3] Asano, T., Murayama, T., Hirai, Y. and Shoji, J. (1993) Comparative Studies on the Constituents of Ophiopogonis Tuber and Its Congeners. VII. Studies on the Homoisoflavonoids of the Subterranean Part of Ophiopogon Japonicas Ker-Gawler cv. Nanus. Chemical and Pharmaceutical Bulletin, 41, 566-570. https://doi.org/10.1248/cpb.41.391

[4] Tada, A., Kasai, R., Saitoh, T. and Shoji, J. (1980) Studies on the Constituents of Ophiopogonis Tuber. VI. Structures of Homoisoflavonoids. Chemical and Pharmaceutical Bulletin, 28, 2039-2044. https://doi.org/10.1248/cpb.28.2039

[5] Watanabe, Y., Sanada, S., Ida, Y. and Shoji, J. (1985) Comparative Studies on the Constituents of Ophiopogonis Tuber and Its Congeners. IV. Studies on the Homoisoflavonoids of the Subterranean Part of Ophiopogon Ohwii Okuyama and Ophiopogon Jaburan (Kunth) Lodd. Chemical and Pharmaceutical Bulletin, 33, 53585363. https://doi.org/10.1248/cpb.33.5358

[6] Zhou, C.X., Zou, L., Mo, J.X., Wang, X.Y., Yang, B., He, Q.J. and Gan, L.S. (2013) Homoisoflavonoids from Ophiopogon japonicus. Helvetica Chimica Acta, 96, $1397-$ 1405. https://doi.org/10.1002/hlca.201200493

[7] Chang, J.M., Shen, C.C., Huang, Y.L., Chien, M.Y., Ou, J.C., Shieh, B.J. and Chen, C.C. (2002) Five New Homoisoflavonoids from the Tuber of Ophiopogon japonicus. Journal of Natural Products, 65, 1731-1733. https://doi.org/10.1021/np0202040

[8] Kumar, R., Ilyas, M., Parveen, M. and Shafiullah (2006) A New Chromone from Cassia nodosa. Journal of Asian Natural Products Research, 8, 595-598.

https://doi.org/10.1080/10286020500179470 
[9] Kirkiacharian, S., Tongo, H.G., Bastide, J., Bastide P. and Grenie, M.M. (1989) Synthe'se et Activite's Angioprotectrice, Anti-Allergique et Antihistaminique de Benzyl-3 Chromones (Homo-Isoflavones) Synthesis and Angioprotective, Antiallergic and Antihistaminic Activities of 3-Benzyl-Chromones (Homoisoflavones). European Journal of Medicinal Chemistry, 24, 541-546. https://doi.org/10.1016/0223-5234(89)90060-3

[10] Siddaiah, V., Rao, C.V., Venkateswarlu, S. and Subbaraju, G.V. (2006) A Concise Synthesis of Polyhydroxydihydrochalcones and Homoisoflavonoids. Tetrahedron, 62, 841-846. https://doi.org/10.1016/j.tet.2005.10.059

[11] Aghoramurthy, K., Narascimhachari, N. and Seshadri, T.R. (1951) Synthetic Experiments in the Benzopyrone Series. Part XVI. Isoformononetin and Its Derivatives. Proceedings of the Indian Academy of Sciences-Section A, 33, Article No. 257. https://doi.org/10.1007/BF03173259

[12] Ahluwalia, V.K., Bhagat, P., Agarwal, R. and Chandra, R. (2005) Intermadiates for Organic Synthesis. I K International Publishing House, Delhi.

[13] Brophy, J.J., Fookes, C.J.R. and Houset, A.P.N. (1992) 2,4,6-Trimethoxytoluene from the Genus 'Stockwellia'. Phytochemistry, 31, 324-325.

https://doi.org/10.1016/0031-9422(91)83064-R

[14] Babu, A.V., Rambabu, A., Giriprasad, P.V., Chandra Rao, R.S. and Babu, B.H. (2013) Synthesis of $( \pm)$-Pisonivanone and Other Analogs as Potent Antituberculosis Agents. Journal of Chemistry, 2013, Article ID: 961201. https://doi.org/10.1155/2013/961201 